Metal finishing. One of the main investigations in the relatively newly formed Metal Finishing Laboratory at Euston Street is on the use of nickel in electroplating. Other researches in that field, designed to improve technique, are those on the electroplating of aluminium and on chromium deposition. The plating of aluminium is difficult, due to a tendency of the basis metal to form a film which prevents proper adhesion of the deposit. This is overcome by the initial formation of a thin zinc coating in one of two ways: chemical replacement, or electrodeposition. The conditions necessary to secure the optimum results in both these methods have been worked out, with marked improvement in industrial practice as a result.

Analysis. In the analytical field, the Association is responsible, apart from a vast amount of analysis required in its own investigations, for the development of new methods and apparatus. The exhibits during the open days covered an extremely wide variety of analytical methods, including the determination of gases in metals. In the chemical field great use is made of the polarograph (including derivative polarography) and of the spectrophotometer. In the field of spectrographic analysis, the Association has been responsible for a great deal of work aimed at improving the range and accuracy of the method. A direct-reading spectrograph (Quantometer) has recently been acquired, designed for the examination of copper alloys. The accuracy and field of use of this instrument are being explored in the light of its known success in the aluminium and steel industries.

\section{DEODAR AS PENCIL WOOD}

T NTIL recently the so-called East African cedar (Juniperus procera) from Kenya has held sway in Britain, the United States and elsewhere as providing the highest class of pencil. Formerly the eastern red cedar of America (Juniperus virginiana) was widely used for pencil-making in the United States; but supplies gave out and the Kenya cedar held pride of place for the best-class and highestpriced pencil. Another tree used for this purpose in the United States is the incense cedar (Libocedrus decurrens), which grows in California. The use of the beautiful Indian deodar wood (Cedrus deodara) for pencil slats is a new idea, due to the research work undertaken at the Research Institute at Dehra Dun, and Indian Forest Bulletin No. 149 (New Series) gives a brief account of this new application*. The deodar has been extensively used in the past for other purposes : after the Sikh Wars in the Punjab (1849), the province was taken over and the British made acquaintance with the deodar, practically the only wood used by the local people, in the building of stations and contonments; later, in the early 1860's, with the coming of the railways, the wood was in even greater demand for making sleepers.

The habitat of the deodar is the north-west Himalaya at approximately $6,500-8,000 \mathrm{ft}$. It has a strong timber, of good grain and easy to work, and is free from warpage. The trees are felled on contracts by the mountain people, converted in situ as required for logs or sleepers and floated down the mountain rivers to the part of the hills where they are collected in

* Indian Forest Bulietin (New Series). No. 149 (Wood Seasoning): Deodar as Pencil Wood. By M. A. Rehman and Jai Kishen. Pp. iv +7 (Delhi : Manager of Publications, 1951.) 5 annas ; $6 d$. depots and built into rafts for the rest of the journey. The forests and work are mostly under the supervision of the government forest department. From the work done at the Institute, it is claimed that the wood makes first-class pencils. Unfortunately, its colour is light yellow; it is thought the public would be suspicious of the unusual colour, so the deodar slats are stained with a dye to a more popular colour. If the deodar pencil can be put on the market at a paying price, the results should be satisfactory, for the consumption in India to-day is about half a million gross of pencils, of which the deodar will supply the demand for higher quality pencils and save imports.

In supplies of material it is hoped to make use of part of the millions of cubic feet of sawn timber extracted every year as shipur; but perhaps more particularly to exploit the huge amount of off-cuts and small pieces left in the forest after the shipur conversion. The bulletin is silent as to the methods by which this material can be collected on the mountain-side in forests where chain-felling is not practical, and it also gives no indication as to the costs of such collection.

\section{EARTHQUAKES DURING 1952}

$\mathrm{D}$ URING 1952 there were eighty-nine earthquakes each having a magnitude 6 or greater than 6 on the Richter logarithmic scale. The greatest two had magnitudes $8 \frac{1}{4}$ and about $8 \frac{1}{3}$, these being rather less than the greatest the world has known. One of the two occurred on March 4 from an epicentre near the east coast of Hokkaido, Japan. Fissures in the earth were caused, and a section of the cliff sank into the sea. Several bridges were damaged, railway lines were buckled and two trains were derailed. When buildings collapsed, fires were started. There was probably some geological fault displacement in the sea-bed also, as a tsunami with waves up to eight feet high swept the coast and swamped a fishing fleet of twenty boats at Uzumai village. At least 31 people were killed and 169 injured, and there was extensive damage to property.

The other earthquake occurred on November 4 from an epicentre near the east coast of Kamchatka (see Nature, 170, 914; 1952). The epicentre, as calculated from observations at eighty-one observatories by the workers at the International Seismological Association Central Station at Strasbourg, was situated at lat. $52 \cdot 9^{\circ} \mathrm{N}$., long. $160 \cdot 1^{\circ} \mathrm{E}$., and the initial time was $10 \mathrm{hr} .58 \mathrm{~min} .23 \mathrm{sec}$. G.M.T. The macroseismic effects in Kamchatka are not yet known, but the earthquake started a great tsunami which spread across the Pacific Ocean and reached as far as the shores of New Zealand, the Hawaiian Islands and South America.

During the past year five earthquakes were reported with a focal depth equal to, or greater than, $400 \mathrm{~km}$., the one with the greatest focal depth $(700 \mathrm{~km}$.) being on February 11 with its epicentre in the Java Sea.

There were a number of earthquakes in or near Europe, and these included the following. On January 3 an earthquake occurred with epicentre near Hasankale in Turkey, Erzurum being affected ; the shock caused damage to some 1,570 houses, and at least 94 persons were killed and 262 injured. On February 7 an earthquake at Arette in the Low Pyrenees, and on February 24 another near Worms 